Proceedings of the 2007 Winter Simulation Conference

S. G. Henderson, B. Biller, M.-H. Hsieh, J. Shortle, J. D. Tew, and R. R. Barton, eds.

\title{
A SIMULATION MODEL WITH A LOW LEVEL OF DETAIL FOR CONTAINER TERMINALS AND ITS APPLICATIONS
}

\author{
Byung-Hyun Ha \\ Eun-Jung Park \\ Chan-Hee Lee \\ Dept. of Industrial Engineering \\ Pusan National University \\ San 30, Jangjeon-dong, Geumjeong-gu \\ Busan 609-735, REPUBLIC OF KOREA
}

\begin{abstract}
As trade among countries grows, the performance of container terminals is becoming more important than ever. In this paper, we present a 3D real-time-visualization containerterminal simulation model based on Plant Simulation, a commercial simulation modeling and execution tool. Our model reproduces every detailed behavior of container-terminal equipment, including not only movements of yard tractors and cranes but also those of trolleys, spreaders, and other machinery. Such low-level representation enables our simulation model to be easily visualized in 3D form and to offer real-time interactive capability. We analyzed the performance of container terminals by varying the settings such as the speeds of trolleys and spreaders, in detail. The simulation model in this study is expected to be useful for assessment of the effects of prospective new equipment on the performance of container terminals and, thereby, for decision-making on the implementation of such equipment.
\end{abstract}

\section{INTRODUCTION}

As trade among countries grows, the performance of container terminals is becoming more important than ever. In particular, after container vessels of more than 10,000 TEU (Twenty-Equivalent Unit) class start on their voyage, the efficiency of discharging and loading containers becomes a question of vital importance for container terminals. The mission of container terminals is to provide customers with high-quality services, and it can be accomplished through improvement of the productivity that depends on efficient equipment, skilled workers, advanced operating systems, and optimal operation schemes. A simulation study is usually carried out to predict the effects on the performance of a container terminal of the application of new elements and schemes are applied, lest such costly ventures fail.
In this paper, we present a $3 \mathrm{D}$ real-time-visualization container-terminal simulation model based on Plant Simulation 7.6, a commercial simulation package. Whereas other studies on container-terminal simulation are carried out by modeling with a rather high level of detail in general, our model focuses on reproducing every detailed behavior of container-terminal equipment, including not only movements of yard tractors or cranes but also those of trolleys, spreaders, and other machinery. Low-detail representation in container-terminal simulation has been overlooked because the objective of simulation usually has been the evaluation of planning schemes and/or dispatching rules for operating container terminals (Kim et al. 2004, Yang, Choi, and Ha 2004). When the purpose of simulation is to assess the correlation between the productivity of container terminals and the capability of equipment used (Kim et al. 2001, Yun and Choi 1999), it is critical to take the detailed operational performance of equipment into consideration. In the case of evaluating operating schemes, low-level representation becomes important as well, because the effectiveness of operating schemes varies according to the operational performance of equipment. We analyzed the performance of container terminals by varying, based on our simulation model, settings such as the speeds of trolleys and spreaders in detail.

The additional advantage of low-level representation is that our simulation model can be easily visualized in 3D form with real-time interactive capability. The benefits to be gained from $3 \mathrm{D}$ visualization of computer simulation are obvious. As noted in Rohrer (2000), high-quality animation can aid simulation processing in the following areas: verification and validation, understanding of results, communication of results, securing buy-in from nonbelievers, and achieving credibility for the simulation. In the case of container terminals, the need to examine simulation results with $3 \mathrm{D}$ visualization is also growing stronger but it seems 
not to be easily fulfilled, due to the difficulties in accessing $3 \mathrm{D}$ visualization techniques (Park et al. 2005). In this paper, we demonstrate the straightforwardness of generating 3D visualization results from a low-detail simulation model in the case of using commercial simulation tools with powerful 3D visualization capability such as Plant Simulation.

The rest of this paper is organized as follows. In Section 2, container terminals are defined and the core components to be modeled are described. In Section 3, our simulation model is presented with the assumptions, and the benefits of a low-level simulation model are discussed and the implementation of 3D visualization is illustrated. After presenting and analyzing the experimental results with regard to berth productivity in Section 4, we conclude the paper.

\section{CONTAINER TERMINAL MODELING}

Container terminals are key hubs of global supply chain networks. The role of a container terminal, as a seamless inter-modal interface between marine and overland transportation, is to stevedore and store containers. In this section, we present the major components and operations of container terminals relevant to our simulation model.

Container terminals handle three types of containers: inbound, outbound, and transshipment. Inbound containers are transmitted to container terminals on board container vessels and are delivered to customers by land via external trucks or railway. Outbound containers are received by overland routes and are loaded into container vessels, after which they begin their voyage by sea. Transshipment containers arrive at container terminals via a container vessel and are reloaded to another vessel instead of being delivered by land. In our simulation model, a container terminal consists of the following four major areas: berths, storage yards, traveling areas, and in/out gates for external trucks. Besides the areas noted above, there are facilities for railway operations in most container terminals. We do not include the railway system in our model, however, because it can be considered as an independent component rather than one that is integrated and coordinated with other container-terminal operations.

Figure 1 is a schematic diagram depicting the types of typical container-handling operation with regard to the four areas. Brief explanations for each operation are as follows.

- Discharging operation: unloading inbound or transshipment containers from a container vessel and placing them in a storage yard

- Loading operation: moving outbound or transshipment containers from a storage yard to a berth and loading the containers onto a container vessel
- Delivery operation: transporting inbound containers from a storage yard to customers through gates in container terminals

- Receiving operation: picking up outbound containers from customers and placing them in a storage yard

- Re-marshalling operation: arranging containers in a storage yard to minimize rehandling in loading and delivery operations

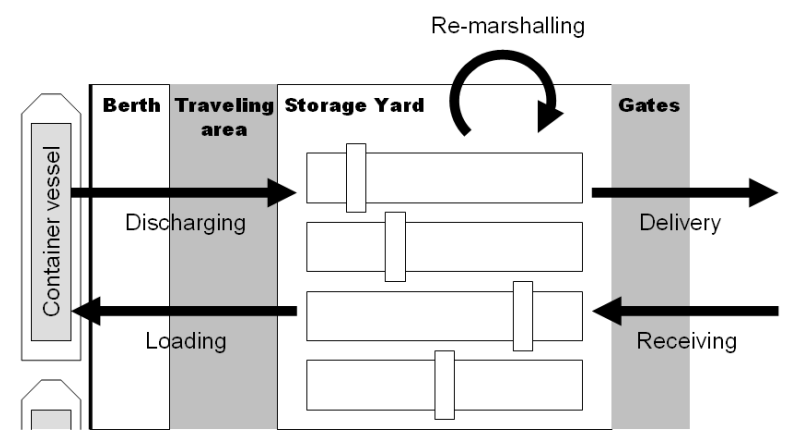

Figure 1: Types of typical container-handling operations in container terminals.

The basic equipments used for handling containers are quay cranes, yard cranes, external trucks, and yard transporters in the traveling area. Examples of yard transporters are yard tractors, shuttle carriers, and AGVs (Automated Guided Vehicles). When a container vessel arrives at a berth, several quay cranes are put in charge of stevedoring containers. While discharging, quay cranes pick up containers from ship bays and load them onto yard transporters. The containers, then, are transferred through the traveling area to blocks in a storage yard and are placed temporarily before they are moved to external trucks for overland transportation or to other container vessels for transshipment. Yard canes place containers into blocks in a container yard by picking them up from yard transporters. Containers to be exported from land-side arrive at a container terminal by external trucks and are taken to container blocks likewise. The containers are picked up and loaded onto a relevant vessel when the vessel arrives. We assume that export containers are loaded after all import containers are discharged. During re-marshalling operation, containers can be relocated not only in the same block where they were originally placed but also in a different block.

In a simulation study on a container terminal, the fundamental descriptions above are required to be modeled. Additionally, in-depth specifications and behavior of components in a container terminal, according to the level of detail of the simulation model, are required for successful studies. For example, in the case that the focus of a simulation study is the long-term performance of a container terminal with regard to the capacity of a yard block (Kia, Shayan, and Ghotb 2002), it is not necessary to consider 


\section{Ha, Park, and Lee}

the specific movement of a transporter in the traveling area. Compared with other simulation studies on container terminals, our simulation model is as adequately detailed to represent every precise behavior of equipments. The notable modeling features of our model are as follows.

First, the particular function of quay and yard cranes is described in detail. The basic function of cranes is to transfer containers and to travel (a crane in a container terminals is not fixed at one location). The function of transferring, again, can be divided into picking-up, vertical/horizontal transference, and release. Specifically, a trolley of a crane moves horizontally and a spreader moves vertically. Our simulation model considers all of the above functions. Hence, cranes in the simulation model operate as in real terminals. As a result, the relevant time to perform each function, according to the specific situation, is taken into consideration.

Second, we develop the logic for realistic movement of transporters in the traveling area. In the case of most simulation studies related to container terminals, due to its complexity it is not easy to consider transportation details. In our model, however, the tracks for possible routes are predefined and transporters move on the tracks. Though this approach does not solve all of the transportation modeling problems, the key issues in the traveling area, such as congestion, can be partially resolved.

Third, each container either in a vessel or a storage yard is treated as a concrete object in the simulation model. Because abundant containers have to be processed in containerterminal simulation, the specific attributes of containers, including their location, are usually left out for the sake of efficiency and avoiding prohibitive complexity. The benefits of modeling each container as an object are not only the possibility of realistic visualization but also the implementation and assessment of planning schemes, such as re-marshalling strategies.

\section{SIMULATION MODEL}

The simulation model in this study was build based on Plant Simulation 7.6 of UGS Corp (<www. ugs. com>). Plant Simulation is one of the most widely adopted commercial simulation modeling and execution software packages in the world. Its modeling language is SimTalk, an objectoriented simulation-modeling language. In Plant Simulation, SimTalk is seamlessly integrated into the visual development environment. Specifically, it supports functionalities of powerful material flow, object handling, and 2D/3D visualization of simulation execution.

We assume that there is a berth in a container terminal and that only one container vessel can be at anchor at a time. For each container vessel, three quay cranes are assumed to be in charge of stevedoring. As stated in the previous section, transporters carry containers between a berth and a storage yard on predefined tracks. In the storage yard, container blocks are laid vertically with regard to the berth. The vertical layout is generally employed in order to avoid congestions in the traveling area when RMGCs (Rail-Mounted Gentry Cranes) are used at a storage yard, and $\mathrm{AGVs}$ are used in the traveling area. Another common layout is the horizontal one, which is usually used with RTGCs (Rubber-Tired Gentry Cranes). We assume one yard crane is provided per container block at the storage yard. Each container block has a capacity of 20 fortyfoot container bays, 6 rows, and 4 tiers (i.e. at most 480 forty-foot containers can be placed in a block). At both ends of a block, there are two groups of transfer points (TPs) where containers are transferred from a yard crane to a transporter and vise-versa. Berth-side TPs are for transporters in the traveling area and gate-side TPs are for external trucks. In a container vessel, there is a ship block where containers are placed, and the capacity of a ship block is 9 forty-foot bays, 10 rows, and 6 tiers (i.e. a vessel can carry 540 containers at most). External trucks arrive at the container terminal, and the inter-arrival time is distributed exponentially. The operation requested by an external truck is randomly determined between delivery and receiving with the same probability.

\subsection{Model Description}

In Plant Simulation, every object falls roughly into one of the following two categories: a material flow object and a moving unit object (MU). A material flow object is used to model an object that generates, destroys, and routes MUs. It is fixed to some place in general. In our simulation model, the following material flow objects in Plant Simulation are used to model the objects in a container terminal.

- $\quad$ Source and Drain object: generating and destroying MUs such as containers, container vessels, and external trucks

- Track object: routes for transporters in the traveling area, external trucks, quay cranes, yard cranes, and container vessels

- Store object: places for containers in container blocks in a storage yard or a container vessel (a place is used to locate several containers piled vertically)

- Method object: operational logics for a container terminal

- Frame object: sub-models in hierarchical simulation modeling, e.g. a container block as sub-model of a storage yard

MUs in Plant Simulation model most of the movable objects on behalf of material flow objects. Their locations and attributes are dynamically determined according to the 


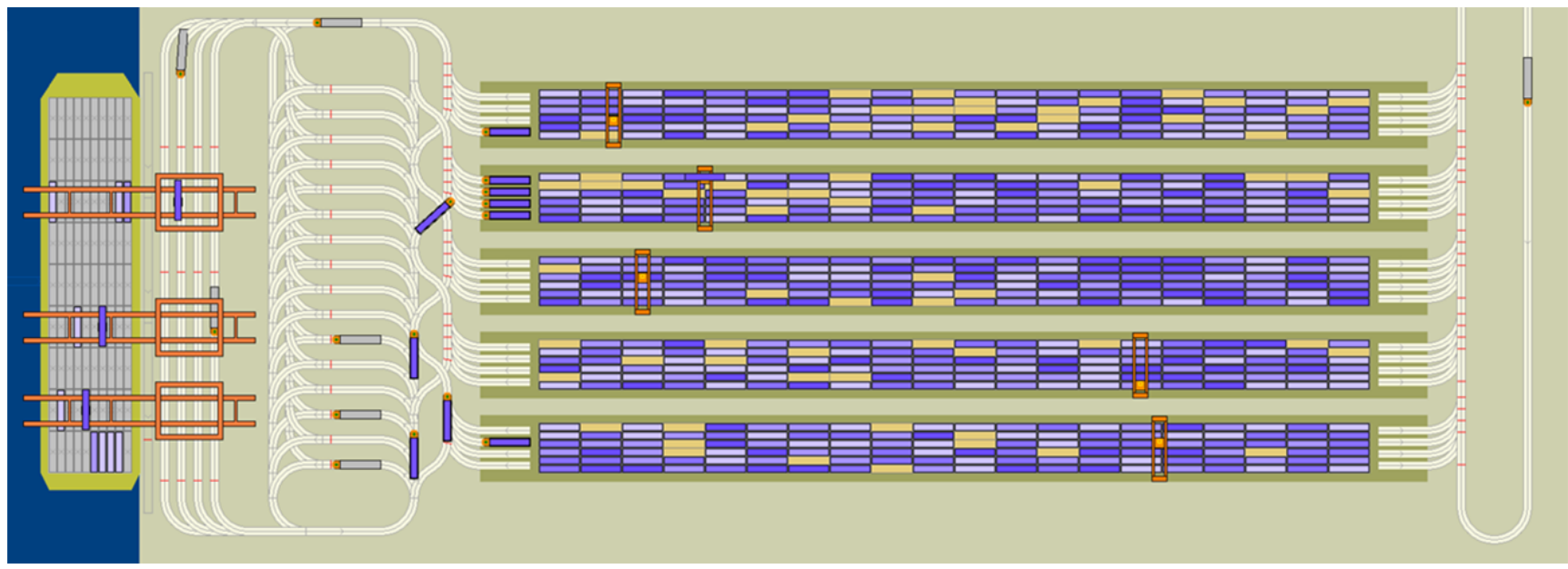

Figure 2: A screenshot of 2D simulation execution.

specific situation. The key objects represented as MUs in our model are quay cranes, yard cranes, transporters (yard tractors), external trucks, container vessel, and containers.

Figure 2 is a 2D visualization of our container-terminal simulation model. At the left is a berth, as well as a container vessel with a ship block. Containers are depicted with blue rectangles. It can be perceived that almost every container is discharged. Three quay cranes, which are color-coded orange, are operating, and empty yard tractors approach to the transfer points under the quay cranes. A yard tractor with a container loaded is color-coded blue on its chassis, and an empty yard tractor is color-coded gray. There are four lanes at a berth side. At the right side of the berth, the traveling area and the storage yard are in sequence. In the traveling area, tracks with complex shape are shown. All of the tracks are one-way in our simulation model. In the center of the traveling area, idle yard tractors stop and wait for new job assignment. There are five container blocks in the storage yard. Each container stack in a block is color-coded a shade of blue. The darker the shade is, the higher the stack is. A yellow container stack means that there is no container. Yard cranes, like quay cranes, are color-coded orange. Berth-side TPs lie at the left of the block, and at the right of the block are TPs for external trucks. It can be seen that an external truck for delivery is approaching to the storage yard.

Track Object in Plant Simulation enables transporters to be routed with less effort. Provided that tracks are properly laid, a modeler need not pay much attention to the traffic control of transporters. They can be routed in a handy way with simple logic. A large part of traffic control, such as collision detection, is accomplished by the Plant Simulation engine. This feature lessens a lot of the burden on a simulation modeler. Nevertheless, modeling appropriate tracks is the task of a human designer, and the model's support of plausible routing depends on the skill of the designer to some degree. Moreover, the task of modeling tracks in Plant Simulation, currently, cannot be fully automated, and requires much endeavor.

To model composite equipment (i.e. equipment with independently operating components) such as quay cranes or yard cranes, each component needs to be modeled separately and be merged into the whole. For example, a quay crane is modeled using the following three objects: a body, a trolley, and a spreader. The body is the basis for the quay crane, and the trolley is placed on the body. In turn, likewise, the spreader is placed on the trolley. The trolley moves across within the body. Hence, the movement of the trolley is horizontal when visualized in 2D. By contrary, the spreader moves vertically, and the movement, obviously, cannot displayed in 2D (the visualization of the spreader movement in $3 \mathrm{D}$ is discussed in the next subsection). Because the movement of a sub-component is similar to that of a transporter on a track, 2D animation of a sub-component is expressed using the concept of an 'animation path' (which can be considered as a kind of track) on an object that includes the sub-component. Figure 3 shows the specification of an animation path for the movement of a quay crane's trolley. Compared with quay cranes in Figure 2, the outline of the crane in Figure 3 can be easily perceived. The straight line marked with ' 1 ' at the center is the animation path for a trolley. Hence, a container, which is conveyed by a spreader connected to the trolley, moves along that line. Likewise, the concept of an 'animation point' is used to placing an MU at a desirable place in the case of Store Object.

For simulation experiments, our simulation system supports dynamic generation of simulation models according to user-defined settings. The following are the types of possible parameters for generating a concrete simulation model: i) the number of blocks in a storage yard; ii) the maximum number of yard tractors, iii) the average arrival rate of external trucks; iv) the moving speeds of quay cranes, yard cranes, yard tractors, and external trucks; and v) the 


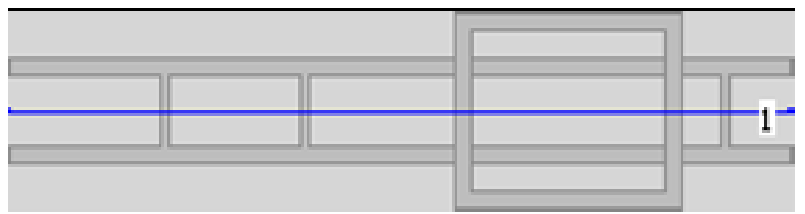

Figure 3: An animation path for visualizing the movement of a quay crane's trolley.

speeds of a trolley and a spreader of a quay/yard crane. The experimental results obtained by varying those settings are discussed in Section 4.

\subsection{VISUALIZATION IN 3D}

Plant Simulation supports automatic generation of information for a 3D visualization in the execution phase with the given simulation model. This functionality can save much time and cost compared with building a custom 3D visualization module. Most commercial simulation tools have such functionalities to satisfy users' demands, and particular pros and cons vary according to the tools. Nevertheless, regardless of the commercial tool used, successful generation of 3D information automatically requires that the movement of objects in the simulation model be described as fully as possible. One of our simulation model's aims was to meet those requirements.

After complementing an existing 2D simulation model with a basic 3D animation capability, appropriate 3D models need to be prepared in order to visualize objects in 3D. Threedimensional models of objects can be designed using the 3D modeling tool bundled with Plant Simulation, or by using external 3D modeling software such as 3D Studio and AutoCAD. Figure 4 depicts a 3D quay crane model in AutoCAD and the resulting 3D model converted for Plant Simulation. After importing the converted 3D model into Plant Simulation, the scale of the imported 3D object needs to be fit to the scale of the whole model.

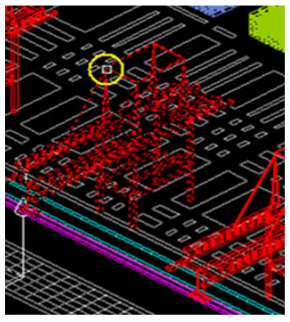

(a)

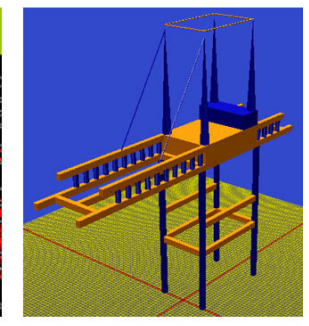

(b)
Figure 4: Generation of a 3D model from a CAD Model. (a) is an AutoCAD model and (b) is a converted 3D model for Plant Simulation.

The next step is to specify the depth (i.e. the coordination with regard to the z-axis) and scale of each 3D model. Note that, with an elaborately implemented simula-

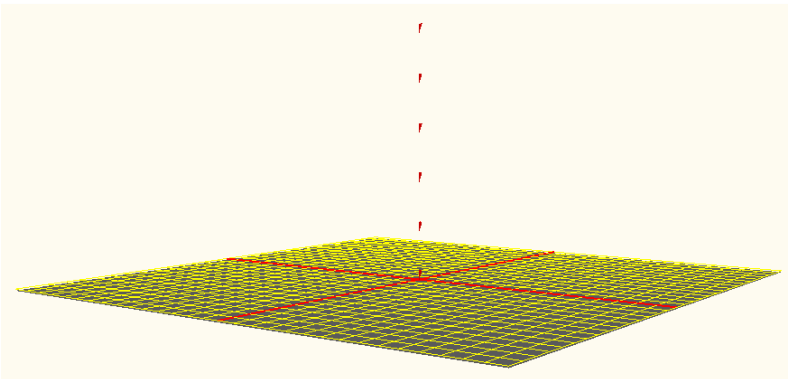

Figure 5: Animation points for visualizing the shape of stacked containers. Containers are located at the animation points (the spot floating over the rectangular plane).

tion model, the location of an object on the $x-y$ plane will already be acceptable, as stated before. For most containerterminal objects, excepting container vessels and containers, it is sufficient to align their bottoms with the ground level. In the case of a container vessel, it is clear that the bottom of the vessel is under the water level. Careful attention is required in order to specify the location of each container, because containers can be stacked vertically one by one, or can be loaded onto a quay/yard crane and a truck. The method of specifying an appropriate location is exactly same as in $2 \mathrm{D}$ cases, and the $3 \mathrm{D}$ animation points are used. Figure 5 shows the resulting animation points for a Store Object, and the animation points enables the shape of stacked containers to be visualized in 3D. Likewise, the 2D animation paths already specified can be reused to express the corresponding 3D coordination, e.g., the movement of a trolley as discussed in the previous section.

Figure 6 presents the resulting 3D visualization of our simulation model. It can easily be perceived that the $x-y$ coordination of the displayed 3D objects is identical to that in 2D (see Figure 2). For visualizing containers in 3D, six 3D models differently color-coded are prepared and used randomly.

One of the limitations of 3D visualization functionality supported by Plant Simulation is that only rigid-body models can be used for visualizing object. A rigid-body model cannot support dynamic shape transformation because simulation timer flies through between simulation events in the case of discrete-event simulation. Hence, it is not easy to visualize a continuously shape-changing object, such as a wire that connects a trolley and a spreader, without a special visualization functionality of a simulation tool. Plant Simulation does not support that feature. To resolve the problem, we devised the technique of using several fragments of a wire and moving the fragments simultaneously along animation paths. That is, a wire is divided into nine fragments and each fragment moves along its own animation path. Hence, the wires of cranes are visualized as if they stretch and shrink. Figure 7 depicts the results.

One of the most important factors in 3D visualization is the tractability of simulation execution. Although 3D vi- 


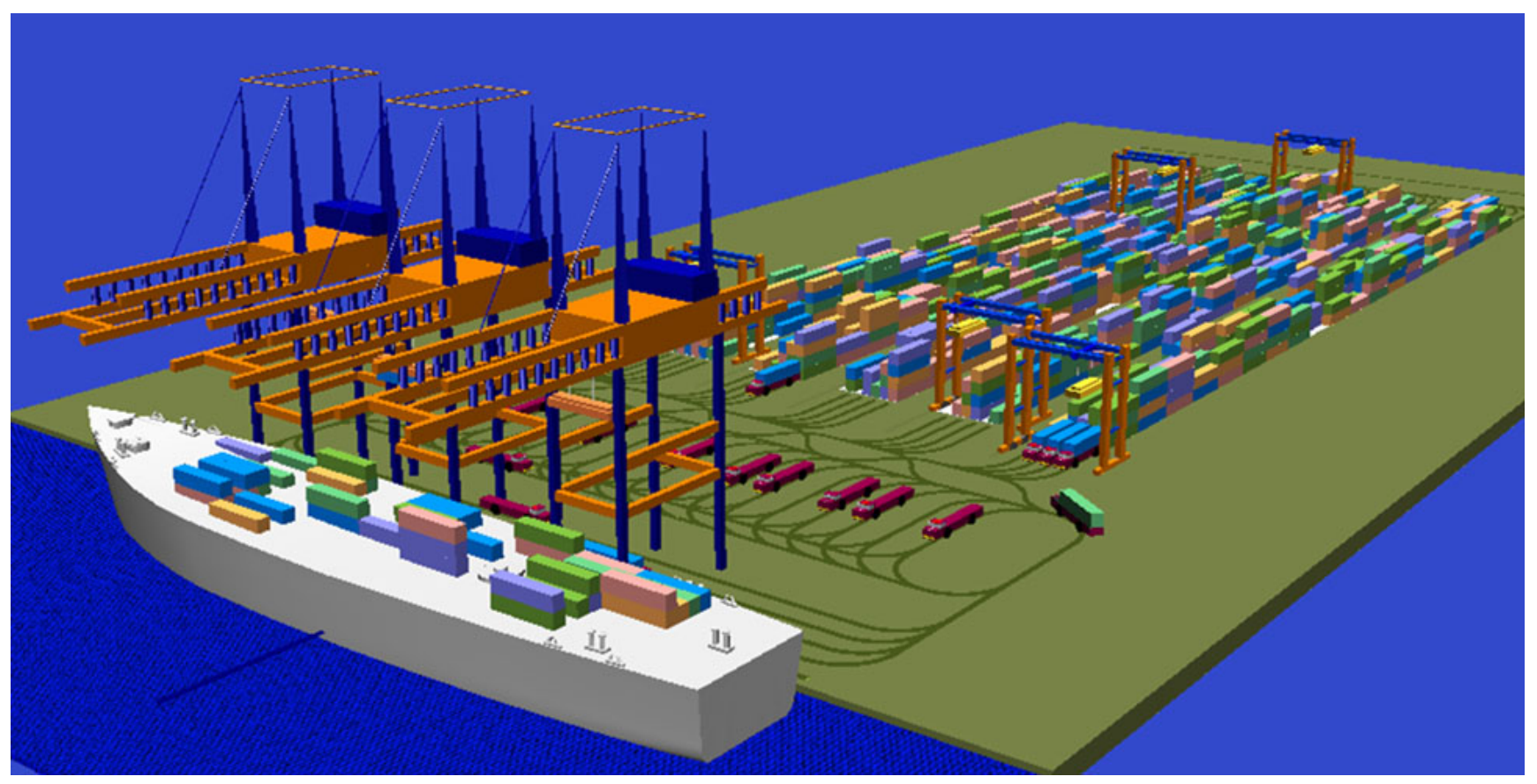

Figure 6: A screenshot of 3D visualization.

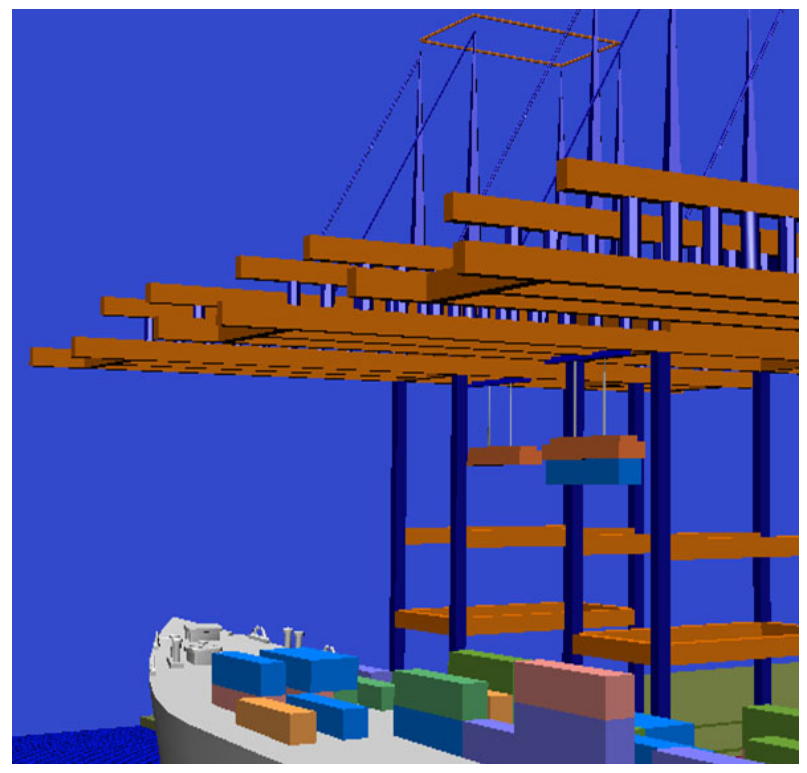

Figure 7: The visualization of wires using fragments and animation paths.

sualization techniques have been improved to great extents, there is still a gap between ideals and practice. We address two factors and experimental results for those regarding the tractability of the visualization of our simulation model in 3D. First, to visualize execution of simulation in 3D, there are two indispensable steps, i.e. initializing and resetting. In the steps, Plant Simulation creates initial objects, and destroys/rearranges the objects in simulation datasets. Table 1 summarizes the results of 3D performance tests with
Table 1: Elapsed time in preparing 3D visualization.

\begin{tabular}{cccc}
\hline $\begin{array}{c}\text { \# of } \\
\text { Containers }\end{array}$ & $\begin{array}{c}\text { \# of } \\
\text { Blocks }\end{array}$ & $\begin{array}{c}\text { Elapsed Time } \\
\text { (Resetting) }\end{array}$ & $\begin{array}{c}\text { Elapsed Time } \\
\text { (Initializing) }\end{array}$ \\
\hline 20 & 3 & $0: 02$ & $0: 07$ \\
20 & 4 & $0: 01$ & $0: 06$ \\
20 & 5 & $0: 03$ & $0: 07$ \\
1000 & 3 & $0: 15$ & $0: 41$ \\
1250 & 4 & $0: 38$ & $1: 12$ \\
1500 & 5 & $0: 55$ & $1: 49$ \\
\hline
\end{tabular}

regard to those two steps. The number in the first column indicates the average number of containers in a simulation model while resetting and initializing. As can easily be seen in the Table, the factor critical to response time is the number of containers (elapses are presented as seconds). Second, the 3D performance in the simulation execution phase is rather irrelevant to the number of containers in the system. The factor critical to 3D performance in the execution phase was proved to be the number of continuously moving objects, such as yard tractors, trolleys, and spreaders. The experiments was carried out on a Pentium4 2.8GHz, 1GByte RAM PC using Microsoft Windows XP.

\subsection{MODEL VALIDATION}

To validate the simulation model, preliminary experiments ware carried out using a typical setting of existing container terminals. At a container terminal in practice, three quay cranes are usually allocated for a berth, and serve a vessel in discharging and loading containers. Also, three-to-five 


\section{Ha, Park, and Lee}

yard blocks supports the stocking of import and export containers. For transferring containers between the berth and the container blocks, two-to-four yard tractors, generally, are assigned to a quay crane. The operational specifications of employed equipment are determined according to real equipments. A detailed description of those specifications is presented in Section 4.

With the above-noted configuration, the simulation results show that the average productivity of a quay crane, that is, the number of moving containers per hour, is about 25 to 30 . The resulting productivity is quite acceptable compared with the performance of quay cranes in practice.

\section{EXPERIMENTS AND RESULTS}

As stated in Subsection 3.1, the performance of a container terminal was assessed by varying the settings. Berth productivity was chosen as the performance measure. The metric adopted was the average number of containers handled by each quay crane. An experiment was completed when 20 container vessels were completely served. Twenty replications of the simulation runs were used to obtain results per a set of parameters. The computer system for experiment was the same as that discussed in the previous section and each experiment took 2 or 3 seconds. The experimental results show that our simulation model can be used to determine the optimal investment strategy with regard to the various constraints including budgets and physical spaces for a container terminal. The performance of a container terminal was evaluated with reference to a quay crane's productivity, which was defined as follows:

total number of discharged and loaded containers

total lay days of vessels $\times$ number of quay cranes

In the first and second experiments tabulated below, the cycle time of the quay cranes was fixed to about $70 \mathrm{sec}$., that is, under optimal conditions a quay crane could discharge and load about 50 containers on average per hour. The optimal productivity of a quay crane is defined according to the mechanical specifications of the crane, and can be accomplished only when there is no wait time during the crane's discharging and loading operation. In most cases, there are numerous situations rendering the crane idle and so the actual productivity is less than the optimal. Note that the crane productivity of 50 movements per hour was determined by considering the actual performance of quay cranes in practice.

First, the effects on the berth productivity were identified by varying the speed of yard cranes and the number of yard tractors. In this setting, the number of container blocks in a storage yard was fixed at 5, and the speed of yard tractors was fixed at $3.8 \mathrm{~m} / \mathrm{s}$. The experimental results are listed in Table 2. From the Table, it can be perceived that the productivity no longer improves when the speed of the yard cranes is greater than about $5.5 \mathrm{~m} / \mathrm{s}$ and the number of yard tractors is greater than about 9. That is, no additional improvement can be achieved with one berth and three limited-performance quay cranes. Hence, it can be seen that investment in equipment would be necessary at the berth-side to increase productivity further. Another interesting implication is that the speed of yard cranes and the number of yard tractors can contribute to berth productivity independently up to a point. In other words, in that area, two factors were proved to be bottlenecks at the same time.

Table 2: Productivity of quay cranes (the number of containers handled/h) according to the speed of yard cranes (YCs) and the number of yard tractors (YTs).

\begin{tabular}{ccccccccc}
\hline \multirow{2}{*}{$\begin{array}{c}\text { Number } \\
\text { of YTs }\end{array}$} & \multicolumn{7}{c}{ Speed of YCs $(\mathrm{m} / \mathrm{s})$} \\
\cline { 2 - 9 } & 2.5 & 3.5 & 4.5 & 5.5 & 6.5 & 7.5 & 8.5 & 9.5 \\
\hline 3 & 9.2 & 10.5 & 11.3 & 11.9 & 12.4 & 12.7 & 13.0 & 13.1 \\
4 & 13.1 & 15.1 & 16.4 & 17.3 & 18.0 & 18.5 & 19.0 & 19.3 \\
5 & 16.1 & 19.0 & 20.7 & 22.0 & 17.9 & 23.7 & 24.1 & 24.5 \\
6 & 18.8 & 22.7 & 24.7 & 26.2 & 25.1 & 27.2 & 28.5 & 29.3 \\
7 & 21.2 & 25.1 & 26.6 & 30.0 & 30.4 & 31.7 & 32.4 & 32.2 \\
8 & 22.5 & 27.1 & 27.9 & 32.4 & 30.3 & 33.8 & 35.2 & 33.6 \\
9 & 23.1 & 28.9 & 28.9 & 34.0 & 34.1 & 33.8 & 35.9 & 36.3 \\
10 & 23.8 & 29.1 & 28.3 & 32.7 & 34.6 & 34.0 & 34.6 & 36.8 \\
11 & 24.9 & 30.8 & 31.9 & 33.8 & 34.3 & 34.8 & 34.8 & 35.9 \\
12 & 25.5 & 30.1 & 32.6 & 33.3 & 34.4 & 36.2 & 36.2 & 35.3 \\
\hline
\end{tabular}

Second, to analyze the effect of the efficiency of a storage yard on berth productivity, similar experiments were carried out with the number of blocks set at 4, 5, and 6 . Along with the number of blocks in the yard, the speed of yard cranes was also considered, because the efficiency of a storage yards depends not only on the former but also on the latter. That is, it can be conjectured that the performance of the storage yard is sufficient to serve the berth operation with efficient equipment (in this case, highspeed yard cranes) even though the number of blocks are insufficient. Table 3 summarizes the results. Consulting the Table, it can be perceived that the optimal number of blocks is 5 , because there is not much improvement in the berth productivity even when the number of blocks is 6 , regardless of the speed of the yard cranes. With regard to the number of yard tractors, it can be seen that the results agree with the first experiments. Considering the effects of the speed of yard cranes on the quay crane performance, it is possible to verify the above conjecture as to the relationship among the number of blocks, the speed of yard cranes, and the performance of the storage yard. That is, with highspeed yard cranes, the number of blocks can be decreased without obstructing the performance of the storage yard. Such results can be considered when the alternatives of hiring high-speed cranes and enlarging the space of the storage yard are compared. 
Table 3: Productivity of quay cranes (the number of containers handled/h) according to the speed of yard cranes (YCs), the number of yard tractors (YTs), and the number of blocks.

\begin{tabular}{cccccccc}
\hline \multirow{2}{*}{$\begin{array}{c}\text { Number } \\
\text { of Blocks }\end{array}$} & Speed & \multicolumn{6}{c}{ Number of } \\
\cline { 2 - 7 } & 2.5 & 15.3 & 17.3 & 18.9 & 19.7 & 21.5 & 21.7 \\
\hline \multirow{4}{*}{4} & 3.5 & 18.4 & 21.6 & 23.5 & 25.2 & 26.2 & 27.2 \\
& 4.5 & 20.4 & 23.8 & 26.2 & 29.1 & 30.7 & 31.2 \\
& 5.5 & 21.7 & 25.5 & 28.5 & 31.4 & 31.5 & 32.2 \\
& 6.5 & 22.5 & 27.0 & 30.1 & 33.8 & 35.0 & 36.1 \\
\hline \multirow{6}{*}{5} & 2.5 & 16.1 & 18.8 & 21.2 & 22.5 & 23.1 & 23.8 \\
& 3.5 & 19.0 & 22.7 & 25.1 & 27.1 & 28.9 & 29.1 \\
& 4.5 & 20.7 & 24.7 & 26.6 & 27.9 & 28.9 & 28.3 \\
& 5.5 & 22.0 & 26.2 & 30.0 & 32.4 & 34.0 & 34.0 \\
& 6.5 & 23.2 & 27.1 & 30.4 & 31.3 & 34.1 & 34.6 \\
\hline \multirow{6}{*}{6} & 2.5 & 16.3 & 19.0 & 21.7 & 23.5 & 25.0 & 26.2 \\
& 3.5 & 18.8 & 22.4 & 25.1 & 28.2 & 27.6 & 29.8 \\
& 4.5 & 20.4 & 24.3 & 27.7 & 29.9 & 31.3 & 33.7 \\
& 5.5 & 21.1 & 25.8 & 28.9 & 32.8 & 33.3 & 35.9 \\
& 6.5 & 22.0 & 26.3 & 30.0 & 33.1 & 34.7 & 35.6 \\
\hline
\end{tabular}

Third, the berth productivities were analyzed by varying the cycle time of the quay cranes and the number of blocks. In these cases, the speed of the yard cranes was fixed at $2.5 \mathrm{~m} / \mathrm{s}$, and the number of yard tractors was fixed at 10. Table 4 summarizes the experimental results. The effect of the number of blocks on the productivity can be recognized, and the results are consistent with the above experiments. One thing of note: when the number of blocks is insufficient, the effect of the cycle time of quay cranes is negligible; and, the contrast, when yard-side capacity is sufficient, the increased performance of quay cranes can improve berth productivity. This speaks to the fact that the performance of container terminals can be improved only when the bottleneck is resolved.

Table 4: Productivity of quay cranes (the number of containers handled/h) according to the number of blocks and the cycle time of quay cranes.

\begin{tabular}{cccc}
\hline Cycle Time & \multicolumn{3}{c}{ Number of Blocks } \\
\cline { 2 - 4 } of QCs & 4 & 5 & 6 \\
\hline 97.80 & 20.71 & 23.44 & 25.13 \\
88.91 & 20.76 & 24.50 & 24.81 \\
80.83 & 21.65 & 24.23 & 25.03 \\
73.48 & 21.80 & 24.10 & 26.31 \\
66.80 & 21.27 & 25.20 & 27.60 \\
60.73 & 21.96 & 26.10 & 28.47 \\
\hline
\end{tabular}

\section{CONCLUSIONS}

In this paper, we present a low-detail container-terminal simulation model based on Plant Simulation. Our model represents the particular function of cranes and the movement of transporters in traveling area as well as the basic features of container terminals. With the model, we demonstrate that $3 \mathrm{D}$ visualization can be implemented with relatively little efforts. In addition, a means of polishing automatically generated $3 \mathrm{D}$ visualization is presented in detail. Also various microscopic factors affecting the performance of container terminals are illustrated. The performance of a container terminal is assessed from various viewpoints: i) berth productivity with regard to the speed of yard cranes and the number of yard tractors; ii) berth productivity with regard to the number of blocks and the speed of yard cranes; and iii) berth productivity with regard to the cycle time of quay cranes and the number of blocks. The results show that the operational performance of a container terminal depends on the capacities of the components constituting the terminal. It is further inferred that the capacities of the components need to be improved evenly to increase the productivity of a container terminal.

Our future research priorities are twofold. The first is to eliminate the assumptions in our simulation model. Although the simulation model is validated, there are too many assumptions in our model to adequately reflect realworld container terminals. We expect that further work will allow us to eliminate the assumptions with less difficulty. The second priority is to better, more thoroughly elucidate the correlation between the productivity of a container terminal and the capacities of its components. The results are expected to be effectively employable in determining optimal investment alternatives with regard to the various constraints, including budgets and spaces.

\section{ACKNOWLEDGMENTS}

This work was supported by the Korea Research Foundation Grant funded by the Korean Government (MOEHRD) (Research Center for Logistics Information Technology, The Regional Research Universities Program).

\section{REFERENCES}

Kia, M., E. Shayan, and F. Ghotb. 2002. Investigation of port capacity under a new approach by computer simulation. Computers \& Industrial Engineering 42:533-540.

Kim, K. H., S. H. Won, J. K. Lim, and T. Takahashi. 2001. Berth planning and resources optimisation at a container terminal via discrete event simulation. European Journal of Operations Research 133:537-547.

Kim, K. H., S. H. Won, J. K. Lim, and T. Takahashi. 2004. An architectural design of control software for 
automated container terminals. Computers \& Industry Engineering 64:741-754.

Park, S. C., J. H. Suh, Y. J. Lee, and K. S. Lee. 2005. A development of $3 \mathrm{~d}$ simulator program for performance valuation of port transportation systems. In Proceedings of the International Conference on Control, Automation, and Systems. GyeongGi-Do, Korea.

Rohrer, M. W. 2000. Seeing is believing: The importance of visualization in manufacturing simulation. In Proceedings of the 2000 Winter Simulation Conference. Orlando, FL.

Yang, C. H., Y. S. Choi, and T. Y. Ha. 2004. Simulationbased performance evaluation of transport vehicles at automated container terminals. OR Spectrum 26:149170.

Yun, W. Y., and Y. S. Choi. 1999. A simulation model for container-terminal operation analysis using an objectoriented approach. International Journal of Production Economics 59:221-230.

\section{AUTHOR BIOGRAPHIES}

BYUNG-HYUN HA is an assistant professor in the Department of Industrial Engineering at Pusan National University. He received his Ph.D. degree in Industrial Engineering from the Seoul National University, Korea in 2005. His scientific interests are in the field of logistics systems, simulation, process management, ontology, knowledge bases, and medical imaging.

EUN-JUNG PARK is a master's candidate in the Department of Industrial Engineering at Pusan National University. She received her bachelor degree in Computer Science from the TongMyung University, Korea in 2005. Her interests are in the field of computer simulation, semantic web, and logistics management.

CHAN-HEE LEE is a master's candidate in the Department of Industrial Engineering at Pusan National University. She received her bachelor degree in Management Information Systems from the KyungSang University, Korea in 2001. Her interests are in the field of management information systems, decision support systems, simulation, and product lifecycle management. 